\title{
NUMERICAL ANALYSIS OF CELLULAR STEEL BEAMS FAILURE MODES IN FIRE CONDITIONS
}

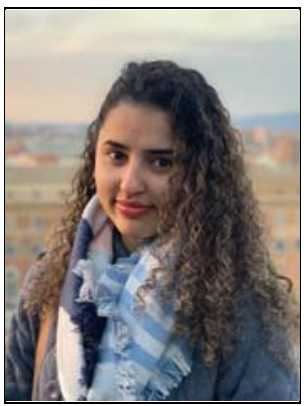

Jaqueline Alves da Silva

Master student IPB, UTFPR

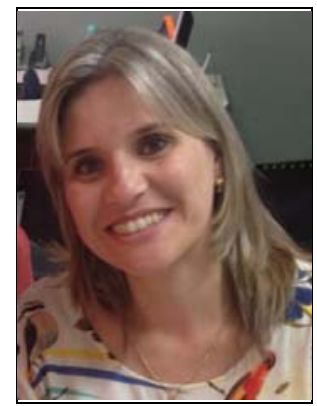

Paola Regina

Dalcanal

Professor

UTFPR-Paraná

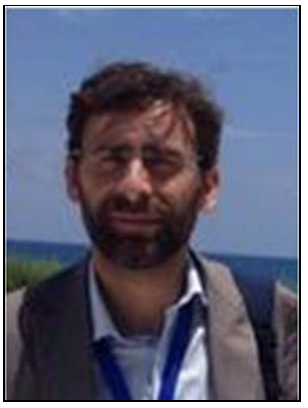

Luís Manuel R. de

Mesquita*

Professor

IPB-Bragança

Keys-word: Cellular beams; Fire Resistance; Failure modes; Numerical modelling.

\section{INTRODUCTION}

Cellular beam generally originates from steel hot-rolled I-section member, which the web is cut, displaced and subsequently welded (Westok method) to obtain openings in the web spaced regularly, with different forms like circular, sinusoidal or hexagonal, see Figure 1. The procedure results in a deeper beam, approximately $40-60 \%$ deeper than its parent solid section, [1]. This type of beam is increasingly used because it is capable to support long spans, it can have a bending resistance up to 2.5 times higher than its parent section and its openings allow the passage of technical equipment and ventilation systems through their web, which reduces the floor height and therefore the overall height of building.

The presence of the opening influences in the failure modes of the beam. Vierendeel mechanism and web post buckling (WPB) are examples of failure modes originate due the openings, while already existing failure modes on solid beams are modified in cellular beams, such as lateraltorsional buckling (LTB), [2]. Besides that, exposure to high temperatures has a detrimental effect on the steel resistance, which added to the initial imperfections of the beam results in the combination of failure modes previously mentioned.

For that reason, the main purpose of the study will be to define the failure modes, in particular WPB and LTB, and the beam resistance, relating the temperature with variant geometric

*Luis Mesquita - Aplied Mechanics Department, Polytechnic Institute of Bragança. Campus Santa Apolónia, 5301-857 Bragança.

Telef.: +351273 303061, Fax: +351273 303116, E-mail: Imesquita@ipb.pt 
parameters, comparing the results obtained by simple calculation methods proposed by Eurocode 3 and Steel Construction Institute (SCI) with numerical results. For this purpose, a finite element model is developed in the software Ansys to study the influence of different geometric parameters, considering geometric imperfections and residual stresses in the beams. Results are compared considering different geometric characteristics and temperatures with design values obtained from the Eurocode EC3-1-2 and the Eurocode new draft EC3-1-13, [3].
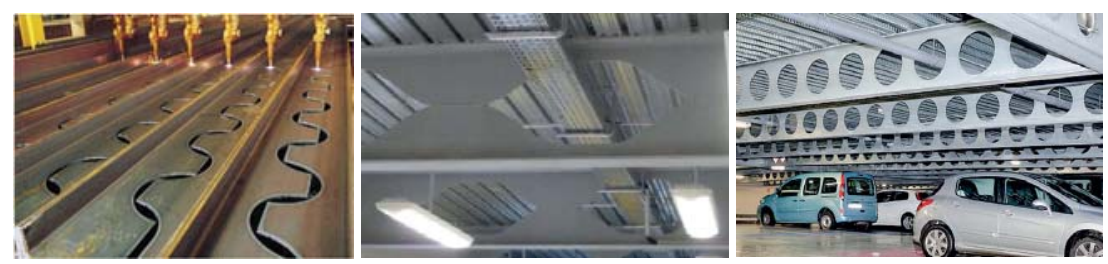

Figure 1 - The cutting process of cellular beams. The use of cellular beams in buildings, [4].

\section{SIMPLE CALCULATION METHODS}

In the present paper, the parent solid section of the cellular beams is a hot rolled I-section IPE500 of class 1 cross-section. It was chosen the steel grade S355 to the study, because of it is the most applied in cellular beams construction due its greater resistant capacity. The cellular beam is considered a double-symmetric beam with the main geometric dimensions presented in Figure 2, such as the variation of spacing between the web openings $(\mathrm{S})$ and the web-post width $\left(S_{0}\right)$, with the length of the member $(L)$ varying in each numerical simulation.
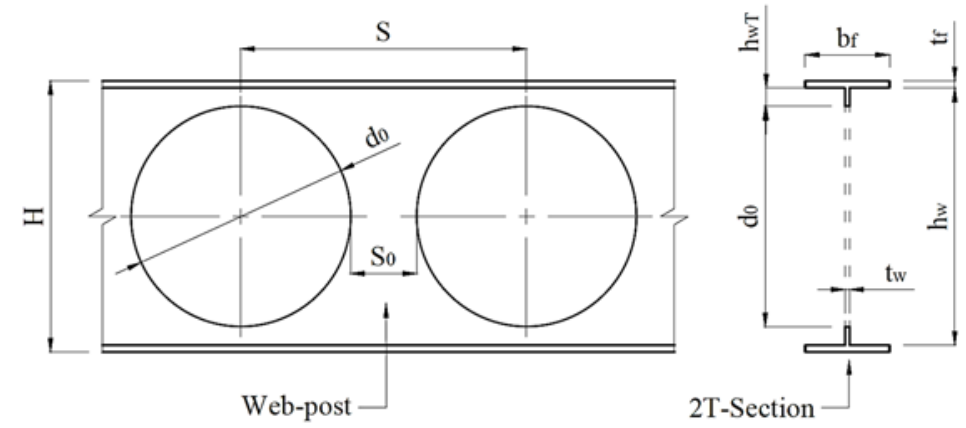

Figure 2 - Cellular beam geometric parameters.

Besides the already mentioned parameters, the other dimensions of the beam illustrated are opening diameter $\left(d_{0}\right)$, flange width $\left(b_{f}\right)$, flange thickness $\left(t_{f}\right)$, height of one Tee $\left(h_{w T}\right)$, height of the web $\left(h_{w}\right)$ and total beam height $(\mathrm{H})$. Some geometric parameters vary in relation to the height of the parent section $(\mathrm{h})$ or the opening diameter according to their use, see table 1 . Thus, this paper will consider this variations during the numerical simulations, according to the specific focus shown in table 2.

In a cellular beam submitted to a design degree of utilisation in fire conditions, web post failure may occur before the section reaches the critical temperature obtained members in bending. This 
fact is mainly due to web height, slenderness and because the temperature of the web-post increases at a faster rate compared to its equivalent (similar web size) solid beam. Beam failure may occur by local buckling instability of the web-post or by Vierendeel bending at the openings.

Table 1 - Variation of dimensions according to the application, [4].

\begin{tabular}{ccccc}
\hline Objective & Application & $\boldsymbol{d}_{\mathbf{0}}$ & $\mathbf{S}$ & $\mathbf{H}$ \\
\hline $\begin{array}{c}\text { Optimization of the } \\
\text { height/weight ratio }\end{array}$ & $\begin{array}{c}\text { Roofing, Footbridges and } \\
\text { Wide-Span purlins }\end{array}$ & $1.0-1.3 \mathrm{~h}$ & $1.1-1.3 d_{0}$ & $1.4-1.6 \mathrm{~h}$ \\
\hline $\begin{array}{c}\text { Optimization of } \\
\text { load/weight ratio }\end{array}$ & $\begin{array}{c}\text { Floors, Parking structures } \\
\text { and Offshore structures }\end{array}$ & $0.8-1.1 \mathrm{~h}$ & $1.2-1.7 d_{0}$ & $13-1.4 \mathrm{~h}$ \\
\hline
\end{tabular}

Table 2 - Cases analysed according to the specific focus

\begin{tabular}{ccccccc}
\hline Focus & Type & $\boldsymbol{d}_{\mathbf{0}}$ & $\mathbf{S}$ & $\mathbf{H}$ & $\mathbf{L}(\mathbf{m})$ & $\mathbf{T}\left({ }^{\circ} \mathbf{C}\right)$ \\
\hline $\begin{array}{c}\text { Comparison } \\
\text { between solid and } \\
\text { cellular beams }\end{array}$ & Solid & - & - & $\mathrm{h}$ & $2-10$ & $20,500,600,700$ \\
\cline { 2 - 7 } & Cellular & $1.0 \mathrm{~h}$ & $1.4 d_{0}$ & $1.5 \mathrm{~h}$ & $2-10$ & $20,500,600,700$ \\
\hline $\begin{array}{c}\text { Spacing between } \\
\text { web openings effect }\end{array}$ & Cellular & $1.0 \mathrm{~h}$ & $1.4 d_{0}$ & $1.5 \mathrm{~h}$ & $3,5,7,9,10$ & $20,500,700$ \\
\cline { 2 - 7 } & Cellular & $1.0 \mathrm{~h}$ & $1.7 d_{0}$ & $1.5 \mathrm{~h}$ & $3,5,7,9,10$ & $20,500,700$ \\
\hline
\end{tabular}

The only design guides for beams with web openings at ambient temperature are the annex $\mathrm{N}$ from Eurocode EN1993-1-1 [5], draftEN1993-1-13 [3], P100 [6] and P355 from SCI, [7], and no guides are available for these beams at elevated temperatures. Considering this references and the Eurocode for fire deign EN1993-1-2 [8], the formulae for the different ultimate limit states are presented. These rules follow, the material properties temperature variation accordingly to EN1993-1-2.

\subsection{Plastic bending resistance}

The plastic bending resistance of the beam is calculated by its geometric dimensions and the yield stress of material, for solid and cellular beams. Thus, the expressions based on $[7,9,10]$ are:

$$
\begin{gathered}
M_{f i, \theta, R d}=k_{y, \theta}\left[\gamma_{M, 0} / \gamma_{M, f i}\right] M_{c, R d} \\
M_{c, R d, s}=W_{y} f_{y} / \gamma_{M 0} \\
M_{c, R d, 2 T}=2 A_{T} Z_{c} f_{y} / \gamma_{M 0} \\
M_{p l, R d, 1 T}=\frac{A_{w T} f_{y}}{\gamma_{M 0}}\left(0,5 h_{w T}+t_{f}-Z_{p l}\right)+\frac{A_{f} f_{y}}{\gamma_{M 0}}\left(0,5 t_{f}-Z_{p l}+\frac{Z_{p l}{ }^{2}}{t_{f}}\right) \\
M_{w p, R d}=S_{0}{ }^{2} t_{w} f_{y} / 6 \gamma_{M 0}
\end{gathered}
$$


Where $M_{f i, \theta, R d}$ is the design moment resistance for a uniform temperature, $k_{y, \theta}$ is the reduction factor for the yield stress at the temperature $\theta, M_{c, R d, s}$ is the plastic bending resistance of the solid beam, $M_{c, R d, 2 T}$ is the plastic bending resistance of two Tee, $M_{p l, R d, 1 T}$ is the plastic bending resistance of one Tee, $M_{w p, R d}$ is the bending resistance of a web-post, $W_{y}$ is the plastic section modulus about $y$-axis ( $W_{y}=W_{p l, y}$ for class 1 or 2 cross-sections), $f_{y}$ is the yield stress of steel, $A_{T}$ is the area of one Tee, $Z_{c}$ is the distance from the local centroid of the area of one Tee to the global centroid, $A_{w T}$ is the area of the web of one Tee, $A_{f}$ is the area of the flange of one Tee, $Z_{p l}$ is the depth of plastic neutral axis of Tee from outer face of flange $=\left(A_{f}+A_{w T}\right) /\left(2 b_{f}\right), \gamma_{M, f i}$ and $\gamma_{M 0}$ are partial safety factor in fire situation and ambient temperature, respectively, $\gamma_{M 0}=\gamma_{M, f i}=1$.

\subsection{Lateral-torsional buckling resistance}

The calculation of the lateral-torsional buckling resistance $\left(M_{b, R d}\right)$ at ambient temperature $\left(20^{\circ} \mathrm{C}\right)$ of a laterally unrestrained steel beam is done by the following expressions, [9]. The difference between the calculation of solid and cellular beam is the value adopted to some constants, like warping constant, torsional constant and moment of inertia, which vary with the geometric parameters adopted, hence it must be calculated for each beam. In accordance with the 2Tapproach, cross-sectional properties are computed at the centre of the web opening.

$$
\begin{gathered}
M_{b, f i, t, R d}=\chi_{L T, f i} W_{p l, y} k_{y, \theta, c o m} f_{y} / \gamma_{M, f i} \\
\chi_{L T, f i}=\frac{1}{\phi_{L T, \theta, c o m}+\sqrt{\left[\phi_{L T, \theta, c o m}\right]^{2}-\left[\bar{\lambda}_{L T, \theta, c o m}\right]^{2}}} \\
\phi_{L T, \theta, c o m}=0,5\left[1+\alpha \bar{\lambda}_{L T, \theta, c o m}+\left(\bar{\lambda}_{L T, \theta, c o m}\right)^{2}\right] \\
\alpha=0,65 \sqrt{235 / f_{y}} \\
\bar{\lambda}_{L T, \theta, c o m}=\bar{\lambda}_{L T}\left[k_{y, \theta, c o m} / k_{E, \theta, c o m}\right]^{0,5}
\end{gathered}
$$

Where $M_{b, f i, t, R d}$ is the design buckling resistance moment, $\chi_{L T, f i}$ is the reduction factor for LTB in fire situation, $k_{y, \theta, c o m}$ is the reduction factor for the yield strength and $k_{E, \theta, c o m}$ is the reduction factor for the slope of the linear elastic range, both at the maximum temperature in compression flange, $\phi_{L T, c o m}$ value to determine $\chi_{L T, f i}, \bar{\lambda}_{L T, \theta, c o m}$ and $\bar{\lambda}_{L T}$ are the non-dimensional slenderness for LTB at temperature $\theta$ and ambient temperature, respectively, $\alpha$ is the imperfection factor.

In the study of Real P.V. et al, [11], it is suggested to change the $\alpha$ and $\chi_{L T, f i}$ calculation for solid beams at high temperatures, $\alpha$ varying according to the ratio between beam height and width, type of cross-section and steel grade, and $\chi_{L T, f i}$ according to the type of moment distribution.

$$
\alpha=\beta \sqrt{235 / f_{y}}
$$




$$
\begin{aligned}
& \chi_{L T, f i, m o d}=\chi_{L T, f i} / f \\
& f=1-0.5\left(1-k_{c}\right)
\end{aligned}
$$

Where $\beta$ is the severity factor that is equal to 0.75 for rolled I-section with steel grade S355 and $\mathrm{h} / \mathrm{b}>2, \chi_{L T, f i \text { mod }}$ is a modified reduction factor, $f$ is a value to determine $\chi_{L T, f i, m o d}$ and $k_{c}$ is a correction factor that is equal to 0.91 when distribution moment is parabolic.

\subsection{Shear resistance}

The shear resistance is determined using the shear area of the section $\left(A_{V}\right)$, for solid beam corresponds to the area of the web and for cellular beam is computed as

$$
A_{V}=A_{T}-b_{f} t_{f}+\left(2 r+t_{w}\right) 0,5 t_{f}
$$

Where $r$ is the fillet radius of the parent section. Therefore, the shear resistance of the 2T-section $\left(V_{p l, R d, 2 T}\right)$ and the shear resistance for web-post section $\left(V_{w p, R d}\right)$ are given by

$$
\begin{gathered}
V_{p l, R d, 2 T}=\frac{2 A_{V} f_{y}}{\gamma_{M 0} \sqrt{3}} \\
V_{w p, R d}=\frac{t_{w} S_{0} f_{y}}{\gamma_{M 0} \sqrt{3}}
\end{gathered}
$$

\subsection{Web-post buckling resistance}

This local failure mode occurs only in cellular beams due the combination of horizontal shear and double curvature bending across its height, which causes an inclined compression line across the web post height, [2]. The effect of the presence of an aperture in the web is associated with one inclined edge of the opening is stressed in tension and the opposite edge in compression, a twisting action along the height of the web-post is caused by the buckling, [12], see figure 3 .

That resistance depends on the web-post width $\left(S_{0}\right)$, i.e. the spacing between the edges of the openings, which is considered a beam with closely spaced openings when the $S_{0} \leq d_{0}$ and largely spaced openings when $S_{0}>d_{0}$, [7]. The width influences directly the effective web length $\left(l_{e}\right)$, the length subjected to buckling. The study will focus only on beams with closely spaced openings. 


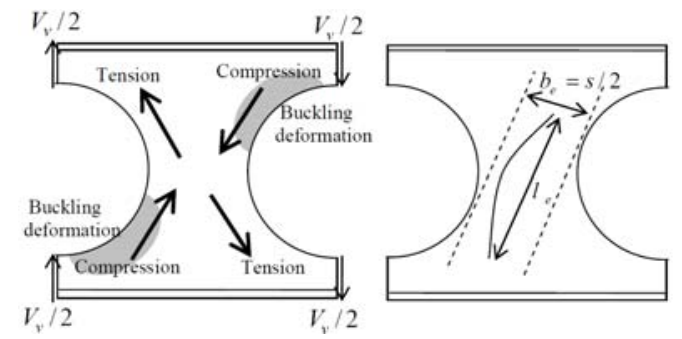

Figure 3 - Strut model of web-post buckling, [13].

The buckling resistance of the web post $\left(N_{w p, R d}\right)$ is determined by the following expressions.

$$
\begin{gathered}
N_{w p, R d}=\chi \frac{S_{0} t_{w} f_{y}}{\gamma_{M 1}} \\
\chi=\frac{1}{\phi+\sqrt{\phi^{2}-\bar{\lambda}^{2}}} \text { but } \chi \leq 1,0 \\
\phi=0,5\left[1+\alpha(\bar{\lambda}-0,2)+\bar{\lambda}^{2}\right] \\
\bar{\lambda}=\frac{2,5 \sqrt{S_{0}^{2}+d_{0}^{2}}}{t_{w}} \frac{1}{\lambda_{1}}
\end{gathered}
$$

Where $\chi$ is the reduction factor, $\alpha$ is the partial factor according to the buckling curve, it is chosen the buckling curve $b$ for cellular beams from rolled sections, [7], $\bar{\lambda}$ is the non-dimensional slenderness of the web-post, $\lambda_{1}$ the geometric slenderness, calculated as in EN1993-1-1.
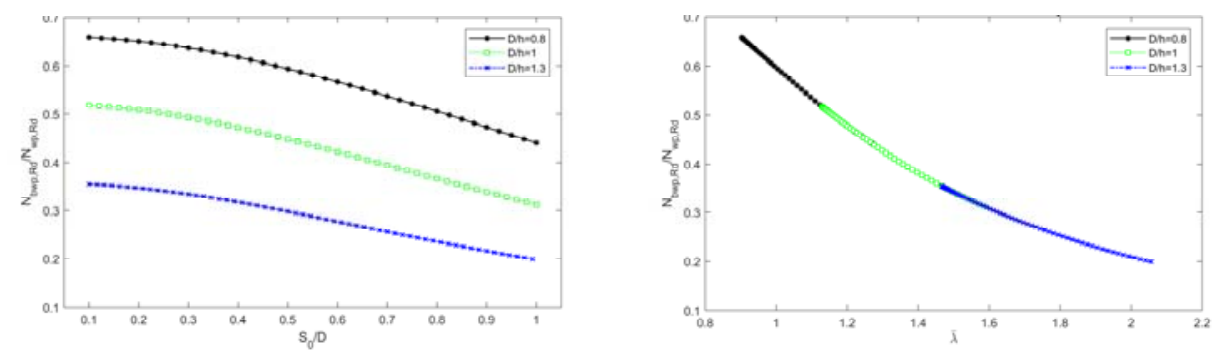

Figure 4 - Web-post buckling resistance in function of the geometric dimensions.

\section{FINITE ELEMENT NUMERICAL MODEL OF SOLID AND CELLULAR BEAMS}

The numerical analysis will be done using Ansys software, by means of the structural element Shell 181 on all surfaces of the beam (flange, web and reinforcing end plate). This finite element has four nodes with six degrees of freedom in each node, which are translations and rotations on $\mathrm{X}, \mathrm{Y}$ and $\mathrm{Z}$ axis, adapted for plasticity and large displacement behaviour. 
The material is defined through the properties of the steel presented in Eurocode EN 1993 1-2, [10], shown in Figure 5. A geometric sinusoidal imperfection is added to the beam with amplitude L/1000 in mid-span, considering the deformed shape from the first buckling mode resulting from the elastic Eigen Buckling analysis.

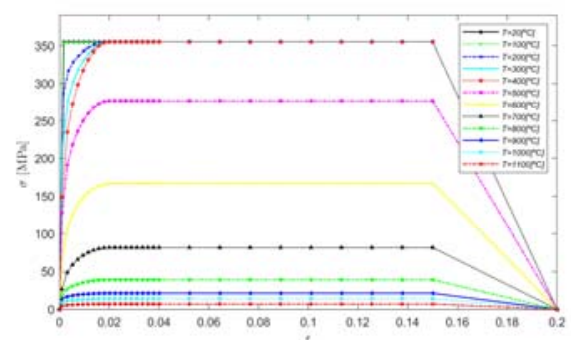

a)

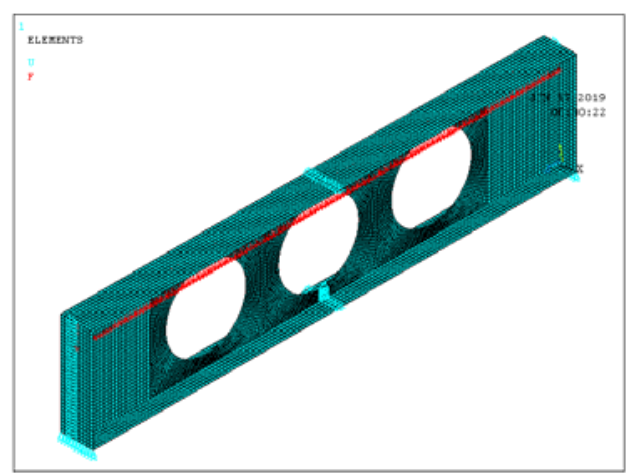

b)

Figure $5-$ a) Stress vs Strain relationship at elevated temperatures. b) Finite element mesh for a cellular beam with: $L=3[\mathrm{~m}], \mathrm{d} 0=1.0 \mathrm{~h}, \mathrm{H}=1.3 \mathrm{~h}$.

In all the studied cases beams are simply supported, with the bottom flange at the ends restrained in vertical direction, the web at the ends restrained in lateral direction, and due the symmetry all nodes at mid-span restrained axially, as presented in Figure 5. The mechanical load is applied as a distributed load in all the centre nodes from the top flange.

The model also considers the influence of residual stress along the beam and its intensity is defined according to the yield stress $\left(f_{y}=355[\mathrm{MPa}]\right)$. For solid beams, the residual stress follows the bi-triangular distribution with maximum amplitude equal to $0.3 f_{y}$, as shown in Figure 6 (a).

For the cellular beams, the residual stress distribution changes, mainly due to the cutting and welding procedure. Taking into account that the introduction of the openings mostly changes the residual stress in the web, due to the insertion of heat in that area, the residual stress in the flange will be considered equal to solid beams and in the web will follow the model proposed in the ECCS document, [14], for a plate with one cut edge, see Figure 6 (b) and the detail (c). It is adopted a tensile stress equal to the yield stress in a narrow strip next to the cut $\left(\sigma_{r}\right)$, with the variable width equal to "c", the opposite edge with the stress value equal to the value considered for solid beams, $\sigma_{t}=0.3 f_{y}$, and the compression stress $\left(\sigma_{c}\right)$ calculated with equation (22), in order to achieve static equilibrium.

A more simplified residual stress pattern follows the recommendation of ECCS (1984) for solid beams, [15], which adopts the triangular distribution from Figure 6 (a) for the flange, while the stresses at the web are considered zero, as presented in Figure 6 (d). This assumes that the whole cutting process dissipates the constraint on the web as shown in figure 12. This model is used by different authors with the assumption that the lateral torsional buckling is mainly affected by residual stresses applied in flanges, $[16,17]$. 


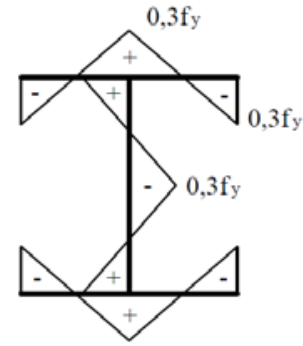

(a)

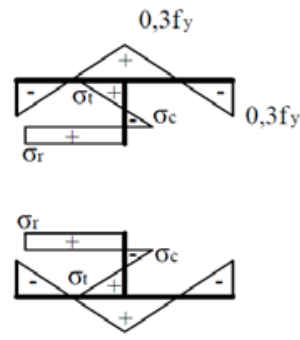

(b)

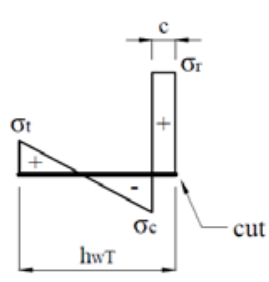

(c)
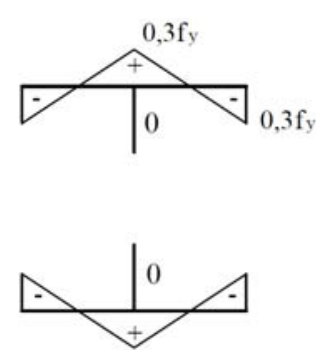

(d)

Figure 6 -(a) Residual stresses on solid beams. (b) Residual stresses on cellular beams (TR2).

(c) Stress distribution in a plate with one cut edge. (d) Simplified residual stress model (TR1).

$$
\sigma_{c}=\sigma_{r} \frac{c\left(4 h_{w T}-c\right)}{(b-c)^{2}}
$$

\section{COMPARISON OF SIMPLIFIED AND NUMERICAL RESULTS}

The Eigen buckling analysis were performed for all solid and cellular beams studied. Figure 7 presents these results for solid and cellular beams of different geometric dimensions (marks). These values are compared with the analytical equation from the ENV1993-1-1 [18] in which all geometric properties consider the $2 \mathrm{~T}$ cross section dimensions.
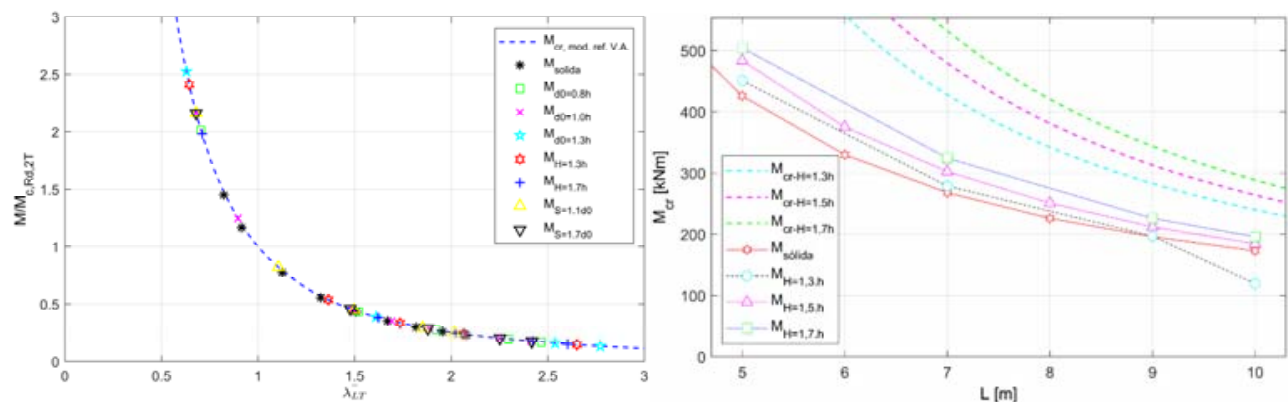

Figure 7. Lateral torsional buckling elastic critical moment for solid and cellular beams.

An iterative procedure was implemented using material and geometric non-linear behaviour and mechanical load increments along the time, considering a uniform temperature distribution over the whole beams. All nonlinear simulations were performed until the beams collapse, defined as the time/load when the numerical convergence was not attained.

Figure 8 presents the numerical simulations of solid beams at ambient and elevated temperatures and their comparison with the simplified methods. In this figure the numerical results consider the Ansys cross section plastic resistance and beam elastic critical moment. 

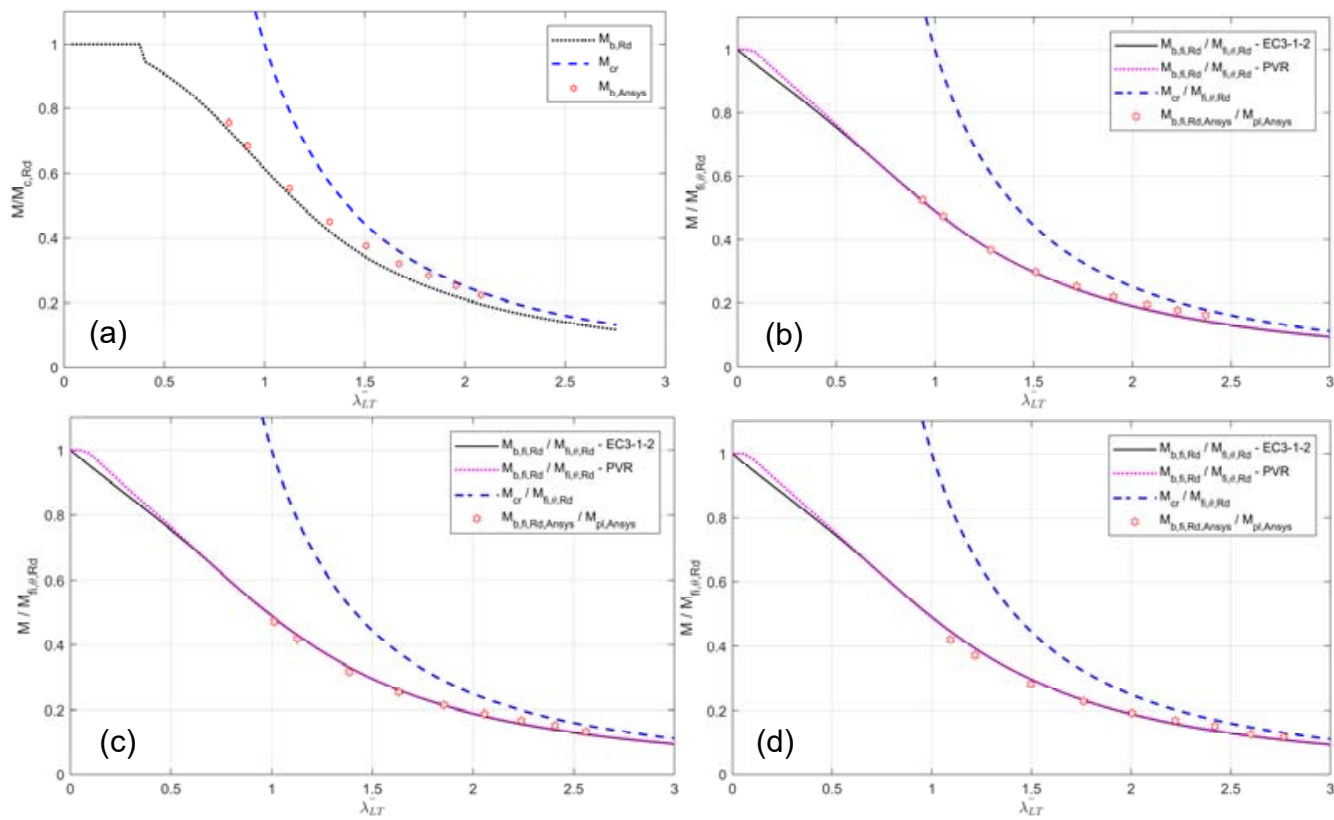

Figure 8. Lateral torsional Buckling resistance of solid beams at different temperatures. (a) 20 ${ }^{\circ} \mathrm{C}$. (b) $500^{\circ} \mathrm{C}$. (c) $600^{\circ} \mathrm{C}$. (d) $700^{\circ} \mathrm{C}$.

A comparison study was done to verify the influence of the residual stress distribution for cellular beams. Several beam lengths were considered for the geometric section with high $\mathrm{H}=1.5 \mathrm{~h}$, whole diameter equal to $\mathrm{h}$, and whole spacing's $S=1.4 \mathrm{~d} 0$. The results are presented in the next figure. It can be seen that for ambient temperature and at $500\left[{ }^{\circ} \mathrm{C}\right]$ the results with TR1 and TR2 give approximately the same results for LTB resistance. This is in line with the knowledge that LTB is more influenced by the flange residual stresses. From this simulations, and due to numerical problems verified in the Newton Raphson method convergence at elevated temperatures, mainly at $800\left[{ }^{\circ} \mathrm{C}\right]$, the next simulations consider the residual stress distribution from TR1.

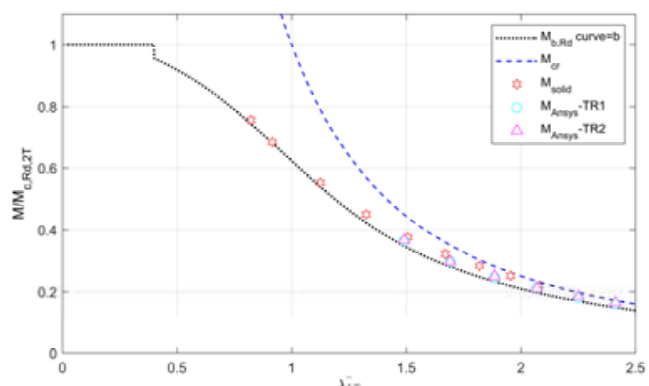

a) $\mathrm{T}=20^{\circ} \mathrm{C}$

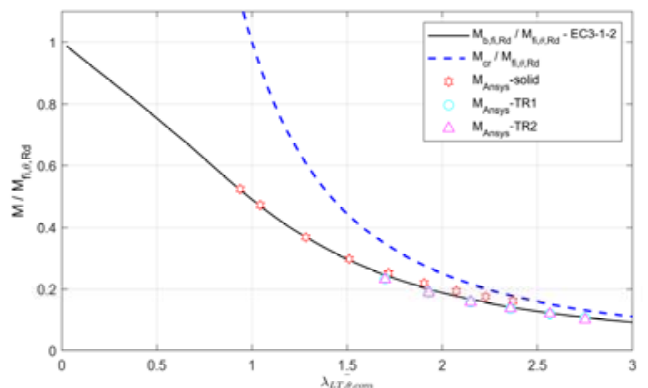

b) $\mathrm{T}=500^{\circ} \mathrm{C}$

Figure 9. Influence of the residual stress distribution on the LTB resistance.

When a cellular beam is subjected to a distributed load, and the geometric imperfections are not considered, the collapse mechanisms are due to shear and bending of the T section or the web post, or even by a combination of both promoting in some geometric configurations the Vierendeel collapse with plastic joints around the wholes. This modes are presented in Figure 10, where, 
considering the reference geometry with $d 0=h, H=1.5 h$ and with spacing's $S=1.4 d 0$, the stress distributions are presented for different beam lengths and temperatures.

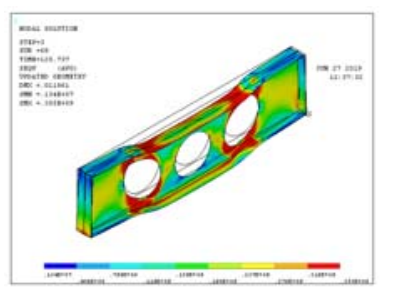

a) $\mathrm{L}=3[\mathrm{~m}], \mathrm{T}=20\left[{ }^{\circ} \mathrm{C}\right]$

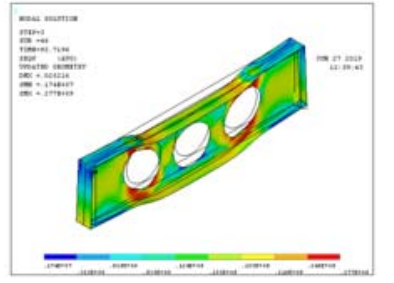

d) $\quad \mathrm{L}=3[\mathrm{~m}], \mathrm{T}=500\left[{ }^{\circ} \mathrm{C}\right]$

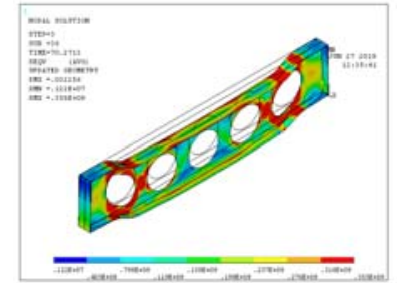

b) $\quad \mathrm{L}=4[\mathrm{~m}], \mathrm{T}=20\left[{ }^{\circ} \mathrm{C}\right]$

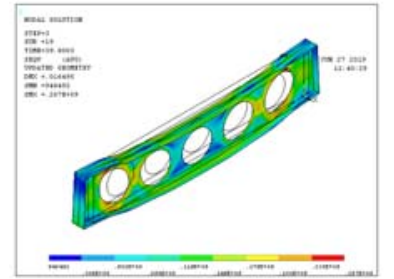

e) $\mathrm{L}=4[\mathrm{~m}], \mathrm{T}=500\left[{ }^{\circ} \mathrm{C}\right]$

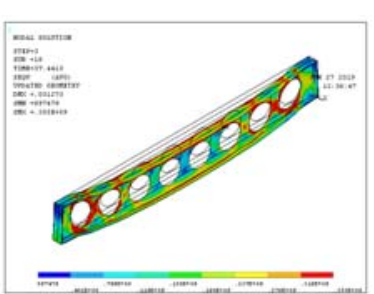

c) $\quad \mathrm{L}=6[\mathrm{~m}], \mathrm{T}=20\left[{ }^{\circ} \mathrm{C}\right]$

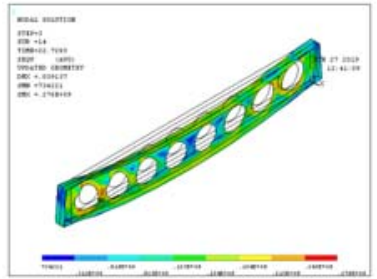

f) $\quad \mathrm{L}=6[\mathrm{~m}], \mathrm{T}=500\left[{ }^{\circ} \mathrm{C}\right]$

Figure 10. Collapse modes of cellular beams without geometric imperfections at ambient temperature and at $\mathrm{T}=500\left[{ }^{\circ} \mathrm{C}\right]$.

For the same cellular beam geometry, Figure 11 present the applied collapse maximum moment normalized by the analytical $2 \mathrm{~T}$ cross section plastic moment resistance. The results at ambient temperature are compared to the results at $\mathrm{T}=500\left[{ }^{\circ} \mathrm{C}\right]$ for different beam lengths, without considering the geometric imperfections (NGI) and considering it (WGI). It can be seen that for the NGI cases, only higher spans fail by bending, while for shorter beams the failure occurs for loads or moments below the $2 \mathrm{~T}$ plastic moment. When the geometric imperfections are considered, WGI cases, the moment resistance increases until a beam length of $4[\mathrm{~m}]$, defined by the cross section plastic resistance, and then starts to decrease as a result of the lateral torsional buckling behaviour. The $500\left[{ }^{\circ} \mathrm{C}\right]$ results follow the same tendency of the ambient temperature results.
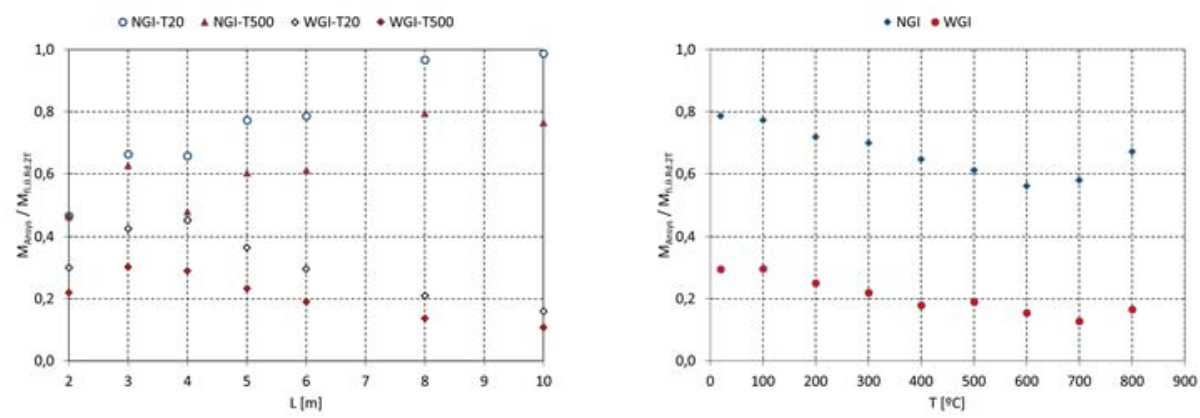

Figure 11. Cellular beams collapse resistance with and without geometric imperfections in function of the temperature.

Figure 11, also presents the resistance of a $6[\mathrm{~m}]$ beam in function of temperature, with and without the geometric imperfections. The results show that this beam fail between 60 to $80 \%$ 
below the $2 \mathrm{~T}$ elevated temperature plastic resistance moment, when is laterally restrained. When LTB collapse mode occur, the resistance reduces to values between 17 to $30 \%$, for temperatures ranges until $800\left[{ }^{\circ} \mathrm{C}\right]$.

In cellular beams, the collapse mode varies with the geometric dimensions. Considering the distance between wholes equal to $S=1.4 d_{0}$, and for beam lengths of 2 and 3 [m], the collapse mode was due to web-post buckling, for all the other analysed was due to LTB. Figure 12 shows the beams von Mises stress distribution in the deformed state at the collapse time/load.

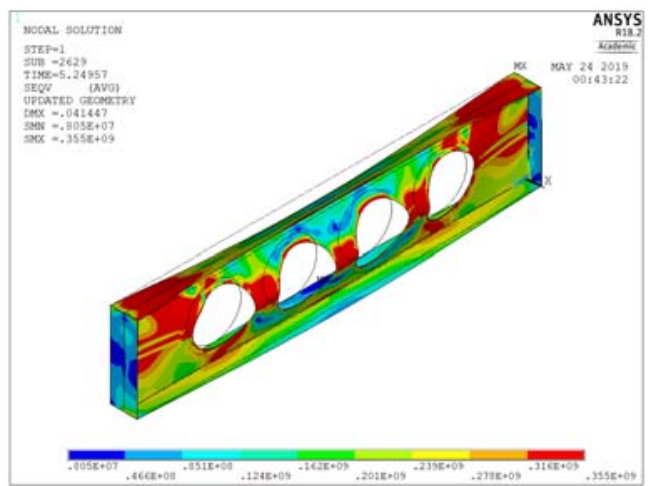

a) $\mathrm{T} 20^{\circ} \mathrm{C}-\mathrm{L} 3 \mathrm{~m}-\mathrm{S} 1.4 d_{0}$

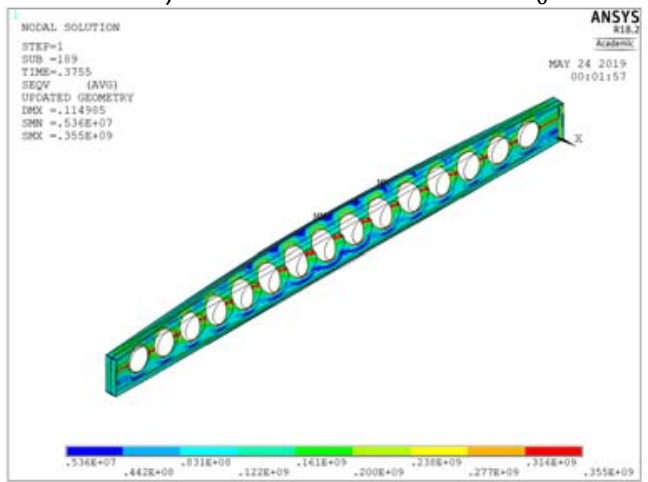

c) $\mathrm{T} 20^{\circ} \mathrm{C}-\mathrm{L} 9 \mathrm{~m}-\mathrm{S} 1.4 d_{0}$

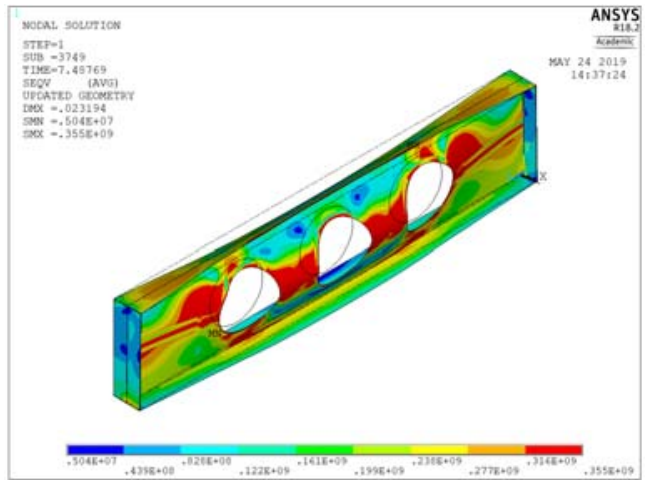

b) $\mathrm{T} 20^{\circ} \mathrm{C}-\mathrm{L} 3 \mathrm{~m}-\mathrm{S} 1.7 d_{0}$

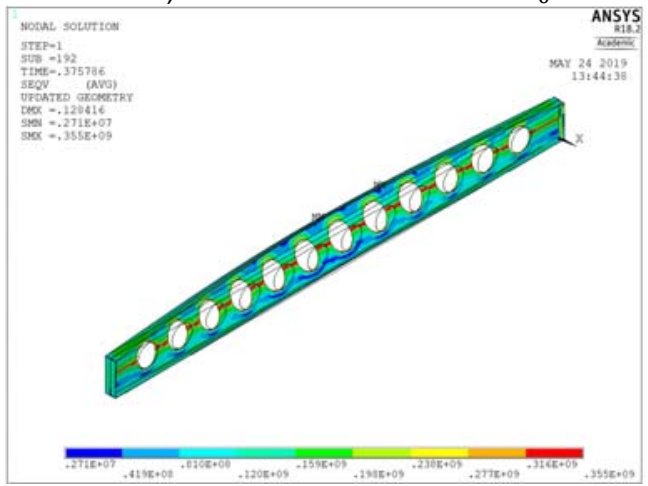

d) $\mathrm{T} 20^{\circ} \mathrm{C}-\mathrm{L} 9 \mathrm{~m}-\mathrm{S} 1.7 d_{0}$

Figure 12. Collapse mode of cellular beams at ambient temperature.

For the cases in which the first buckling mode is not due to lateral torsional buckling, but local buckling or a combination of local and distortional buckling, as for short cellular beams and high section cellular beams, a perturbation method was applied with a lateral load to promote the LTB collapse mode.

A comparison study was made for different lengths and distances between wholes. These results are presented in the next figure in comparison to the buckling curve $b$ for the LTB design and the elastic curve. 


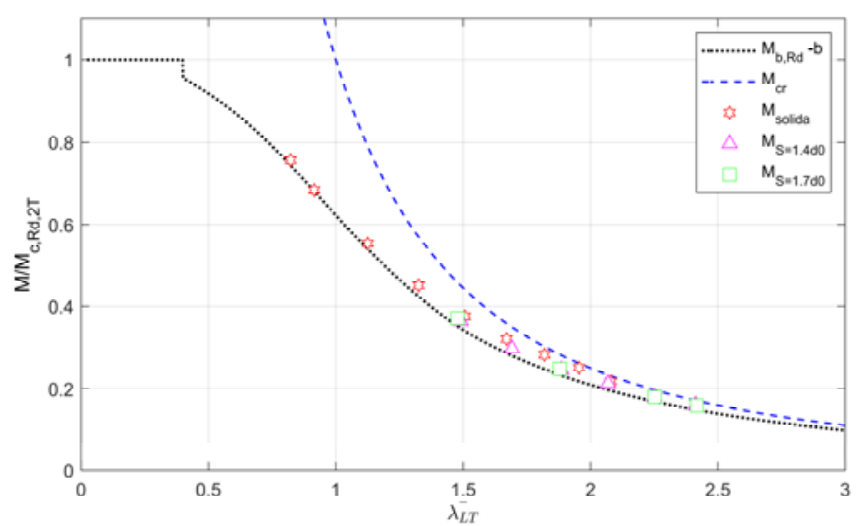

Figure 13. Resistance moment of cellular beams at ambient temperature.

Besides the lateral torsional buckling resistance increases with the spacing increment, from $\mathrm{S}=1.4 \mathrm{~d} 0$ to $1.7 \mathrm{~d} 0$, the normalization results indicates that the design procedure of this beams is safe when the buckling curve $b$ is used.

The results of the whole diameter influence in the moment resistance at ambient and elevated temperatures is presented in Figure 14. For the three cases analysed, the diameter is related with $\mathrm{h}$ and the spacing to the whole diameter ratio constant. The cellular beams with normalized slenderness smaller than unit do not collapse by LTB but mainly due to shear and buckling of the web post, reason for the low resistance moment compared to the curve b design curve.

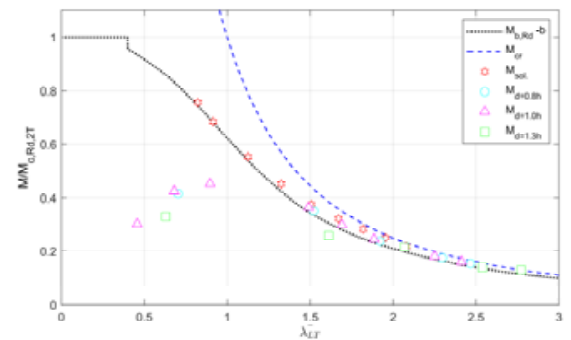

a) $\mathrm{T}=20\left[{ }^{\circ} \mathrm{C}\right]$

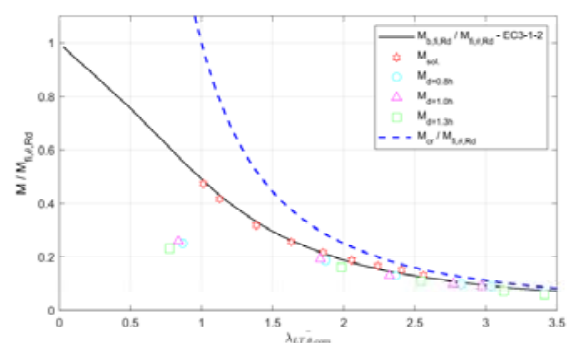

c) $\mathrm{T}=600\left[{ }^{\circ} \mathrm{C}\right]$

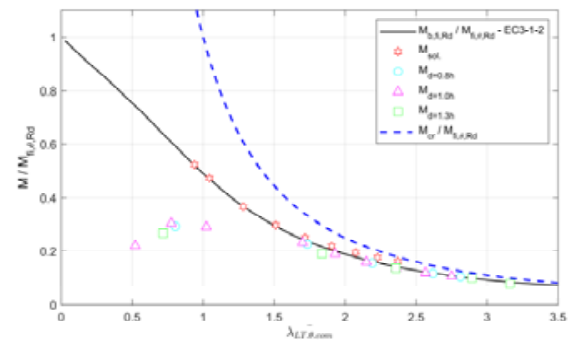

b) $\quad \mathrm{T}=500\left[{ }^{\circ} \mathrm{C}\right]$

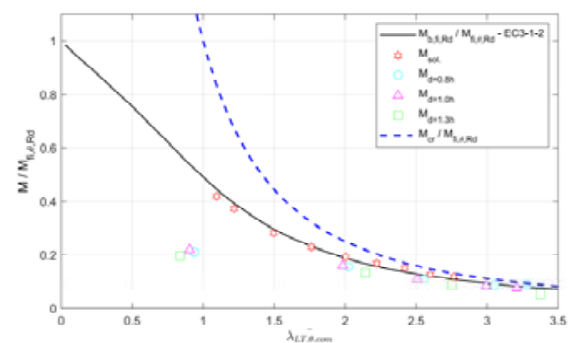

d) $\mathrm{T}=700\left[{ }^{\circ} \mathrm{C}\right]$

Figure 14. Influence of the whole diameter in the moment resistance at ambient and elevated temperatures. 
For the lengths analysed, it was verified that for beams with lengths higher than $4[\mathrm{~m}]$ the collapse mode is always due to LTB for ambient and elevated temperatures. For temperatures between 500 and $700\left[{ }^{\circ} \mathrm{C}\right]$ the difference between the simple calculation method of Eurocode and the numerical results increases with the whole diameter increase.

\section{CONCLUSIONS}

This work presented a simplified method based on the Eurocode formulae and in the SCI reference for the design of cellular beams at ambient and elevated temperatures.

The structural behaviour of solid and cellular beams were compared using non linear geometric and material finite element simulations at different temperatures. Cellular beams resistance varies with the most relevant geometric parameters, namely, the section high, whole diameter and whole spacing.

Even though a cellular beam can have a bending resistance up to 2.5 times higher than its parent solid section new collapse modes, compared to solid sections, can reduce the overall beam resistance, especially for low span beams.

For low span cellular beams, and for the geometric dimensions studied, the achieved collapse modes are due to web post shear and buckling and Vierendeel plastic collapse. For longer spans the collapse mode is mainly due to Lateral torsional buckling.

\section{REFERENCES}

[1] Pachpor, P.D., et al., Finite Element Analysis and Comparison of Castellated and Cellular Beam. Advanced Materials Research, 2011. 264-265: p. 694-699.

[2] Sonck, D., Global Buckling of Castellated and Cellular Steel Beams and Columns, in Department of Structural Engineering. 2014, Faculty of Engineering and Architecture Ghent University. p. 349.

[3] CEN, Draft EN 1993-1-13, Eurocode 3: Design of steel structures - part 1-13: Steel beams with large web openings. CEN/TC 250/SC 4 N 1839 - Web Openings in Steel Beams EC3 Part 1-13. 2017, European Committee for Standardization: Brussels, Belgium.

[4] S.A., A.C.S., ACB® and Angelina ${ }^{\circledR}$ beams - A new generation of castellated beams, ArcelorMittal, Editor. 2018. p. 64.

[5] CEN, ENV 1993-1-1:1992/A2 Eurocode 3: Design of steel structures - Part 1-1: General rules and rules for buildings, Annex N. 1998, European Committee for Standardization: Brussels, Belgium.

[6] Ward, J.K., P100-Design of composite and non-composite cellular beams, ed. S.C. Institute. 1990.

[7] Lawson, R.M. and S.J. Hicks, Design of composite beams with large web openings: In accordance with Eurocodes and the UK National Annexes. 2011, SCI, Silwood Park, Ascot, Berkshire. SL5 7QN UK. p. 1-136. 
Jaqueline A. da Silva, Paola R. Dalcanal, Luís M. R. Mesquita

[8] CEN, EN1993-1-2 Eurocode 3: Design of Steel Structures, Part 1-2: General rules, Structural fire design. 2005, European Committee for Standardization: Brussels, Belgium.

[9] CEN, EN 1993-1-1, Eurocode 3: Design of steel structures - Part 1-1: General rules and rules for buildings. 2010, European Committee for Standardization: Brussels, Belgium.

[10] CEN, EN 1993-1-2, Eurocode 3: Design of steel structures - Part 1-2: General rules Structural fire design. 2010, European Committee for Standardization: Brussels, Belgium.

[11] Vila Real, P.M.M., et al., Parametric analysis of the lateral-torsional buckling resistance of steel beams in case of fire. Fire Safety Journal, 2007. 42(6): p. 416-424.

[12] Demirdjian, S., Stability of castellated beam webs, in Department of Civil Engineering and Applied Mechanics. 1999, McGill University. p. 140 p.

[13] Panedpojaman, P., Buckling analysis for web post of cellular beams. The 10 Intrnational PSU Engineering Conference, 2012: p. 5.

[14] ECCS, Manual on Stability of Steel Structures ( $\left.n^{\circ} 22\right) .1976$.

[15] ECCS, Ultimate Limit State Calculations of Sway Frames with Rigid Joints ( $\left.n^{\circ} 23\right) .1984$.

[16] Sonck, D., N. Boissonade, and R. Van Impe, Instabilities of cellular members loaded in bending or compression. Proceedings of the Annual Stability Conference Structural Research Council, 2012: p. 19 p.

[17] Kwani, S. and P.K. Wijaya, Lateral Torsional Buckling of Castellated Beams Analyzed using the Collapse Analysis. Procedia Engineering, 2017. 171: p. 813-820.

[18] CEN, ENV1993-1-2, Eurocode 3: Design of Steel Structures, Part 1-2: General rules, Structural fire design. 1995, European Committee for Standardization: Brussels, Belgium. 